\title{
NEE SOBRE UMA CULTURA DE ARROZ IRRIGADO NO SUL DO BRASIL
}

\author{
Janaína V.Carneiro1, Débora R. Roberti,
} Hans Zimermann, Marcelo Diaz, Osvaldo L.L.de Moraes

Universidade Federal de Santa Maria - Laboratório de Micrometeorologia - Santa Maria - RS

$$
\text { carneirojana@yahoo.com.br }{ }^{1}
$$

\section{RESUMO}

As médias diárias de carbono $\left(\mathrm{C}-\mathrm{CO}_{2}^{2}\right)$ foram investigadas em um sítio de cultura de arroz irrigado no Sul do Brasil: Cachoeira do Sul (2010-2012). Os dados experimentais foram obtidos através da técnica de covariância de vórtices. A assimilação de $\mathrm{CO}^{2}$ variou com o desenvolvimento da cultura, exibindo uma tendência similar entre os anos de cultivo. Durante a fase VJ, o NEE manteve-se positivo. Para as seguintes fases (VA e R), foi observado um aumento no NEE durante o dia. Na fase final do cultivo do arroz (M), quando a planta começou a amadurecer, o NEE absorvido decresceu significativamente.

\section{INTRODUÇÃO}

O arroz é um dos principais cereais consumidos pela população mundial, com produção aproximada de 590 milhões de toneladas anualmente. O Brasil se encontra entre os dez maiores produtores de arroz no mundo, com cerca de 13 milhões de toneladas produzidas anualmente em 2,8 milhões de hectares (CONAB,2011 - safra 2010-2011). Nos últimos anos, os ecossistemas agrícolas estão ganhando destaque nas observações de trocas de carbono, pois áreas agrícolas podem desempenhar um papel importante no ciclo de carbono terrestre (Campbell et al., 2001; Suyker et al., 2005). As lavouras de arroz irrigado por inundação têm importante função nas trocas globais de gases de efeito estufa, tais como o $\mathrm{CO}_{2}$ e $\mathrm{CH}^{4}$, onde o primeiro é absorvido e o segundo é emitido para a atmosfera (Neue e Sass, 1994; Miyata et al., 2000). Neste trabalho, analisou-se o ciclo médio diário de NEE em área de cultivo de arroz irrigado no RS. 


\section{DESCRIÇÃO DO SÍTIO EXPERIMENTAL E COLETA DE DADOS}

Os dados foram coletados em uma área de cultivo de arroz irrigado, na localidade de Cachoeira do Sul, RS (sítio experimental da rede SULFLUX). Em Cachoeira do Sul, os dados foram coletados a $10 \mathrm{~Hz}$, a uma altura de $3 \mathrm{~m}$ pelo anemômetro sônico e pelo analisador de gás de caminho aberto.

\section{RESULTADOS E DISCUSSÃO}

As médias diárias de NEE e PAR para o sítio experimental estão representadas na figura (1) durante cada fase de desenvolvimento do arroz. Todos os dados, após o preenchimento das lacunas (Falge et al., 2001, Lasslop et al., 2010), foram utilizados para calcular a média. A assimilação de $\mathrm{C}-\mathrm{CO}_{2} 2$ variou com o desenvolvimento da cultura, exibindo uma tendência similar entre os anos de cultivo. Na fase VJ (figura 1a), o NEE manteve-se positivo durante toda a fase. Segundo Nishimura et al. (2008), nesta fase, a quantidade de $\mathrm{CO}^{2}$ absorvido pelas plantas de arroz ainda é inferior ao liberado pela respiração dessas plantas e por microorganismos do solo. Ainda nesta fase, os campos de arroz irrigado têm como produto predominante da decomposição anaeróbica, o $\mathrm{CH}^{4}$ (metano) e não o $\mathrm{CO}^{2}$ (Alberto et al., 2009). Na fase VA (figura 1b), quando as plantas já estão maiores, foi observado um significativo aumento no NEE durante o dia. O NEE próximo ao meio-dia chegou em torno de $-15^{\mu \mathrm{molm}^{-2} \mathrm{~s}^{-1}}$ ano $2010-2011$ e em torno de $-10^{\mu \mathrm{molm}^{-2} \mathrm{~s}^{-1}}$ para o ano seguinte, 20112012. A maior taxa de absorção foi durante a fase R (figura 1c) correspondendo ao período de maior radiação solar. Neste sítio, na cultura de 2010-2011, obteve-se, máximo de absorção de $-25^{\mu \mathrm{molm}^{-2} \mathrm{~s}^{-1}}$ entre $11 \mathrm{~h} 30 \mathrm{~min}$ e $13 \mathrm{~h}$, e no cultivo de 2011-2012, o máximo de NEE foi encontrado entre $11 \mathrm{~h} 30 \mathrm{~min}$ e $13 \mathrm{~h} 30 \mathrm{~min}$, em torno de $-21^{\mu \mathrm{molm}}{ }^{-2} \mathrm{~s}^{-1}$. Na fase final do cultivo do arroz (M) (figura 1d), quando a planta começa a amadurecer, o NEE absorvido decresceu significativamente. Para o período noturno, o NEE foi em média $5^{\mu m o l m}{ }^{-2} \mathrm{~s}^{-1}$ durante as fases de crescimento da planta, com exceção da VJ no ano de 2010-2011 (em torno de $2,5^{\mathrm{umolm}^{-2} \mathrm{~s}^{-1}}$ ). Resultados semelhantes foram encontrados por Alberto et al. (2009) para o período noturno, na qual o NEE foi em torno de $4,5^{\mu m o l m}{ }^{-2} \mathrm{~s}^{-1}$, para todas as fases da cultura. Tseng et al (2010) em estudo durante o período de maturação da planta de arroz, em Taiwan, encontraram NEE em torno de $2,76^{\mu \mathrm{molm}^{-2} \mathrm{~s}^{-1}}$ para o período noturno e de $-7 \mu \mathrm{molm}^{-2} \mathrm{~s}^{-1}$ durante o dia. No sítio de Cachoeira do Sul, os maiores índices de PAR 
foram durante a fase $\mathrm{R}$ no ciclo de cultivo do ano 2011-2012, chegando a atingir um pico de $479 \mathrm{Wm}^{-2}$ (figura 1c).

\section{CONCLUSÕES}

As médias diárias de $\mathrm{C}-\mathrm{CO}_{2}$ foram analisadas em um sítio experimental de cultivo de arroz irrigado na região central do RS, no sul do Brasil (Cachoeira do Sul). Foram utilizados dados observacionais obtidos através do método de covariância de vórtices (EC) e dados após o preenchimento das lacunas. Os dados utilizados compreendem 729 dias (junho de 2010 a maio de 2012). Neste sítio, na VJ, o campo de arroz atuou como fonte de $\mathrm{C}$ nos dois ciclos da cultura. O NEE foi negativo a partir da VA até final da M.

\section{AGRADECIMENTOS}

Projeto SULFLUX (www.ufsm.br/sulflux)

\section{REFERÊNCIAS}

ALBERTO, M.C.R. et al. $\mathrm{CO}^{2}$ /heat fluxes in rice fields: comparative assessment of flooded and non-flooded in the Philippines. Agricultural and Forest Meteorology, v.149, p. 1737$1750,2009$.

CAMPBELL, C.S. et al. Diel and seasonal variation in $\mathrm{CO}_{2}$ flux of irrigated rice. Agricultural and Forest Meteorology, v.108, p. 15-27, 2001.

FALGE, E. et al. Gap filling strategies for defensible annual sums of net ecosystem exchange. Agricultural and Forest Meteorology, v.107, p. 43-69, 2001.

LASSLOP, G. et al. Separation of net ecosystem exchange into nassimilation and respiration using a light response curve approach: critical issues and global evaluation. Global Change Biology. v.16, p.187-208, 2010.

NISHIMURA, S. et al. Effect of land use change from paddy Rice cultivation to upland crop cultivation on soil carbon budget of a cropland in Japan. Agriculture Ecosystems \& Environment. v.125, p.9-20, 2008.

TSENG,K.-H. et al. Determination of methane and carbon dioxide fluxes during the rice maturity period in Taiwan by combining profile and eddy covariance measurements. Agricultural and Forest Meteorology, v. 150, p.852-859, 2010. 


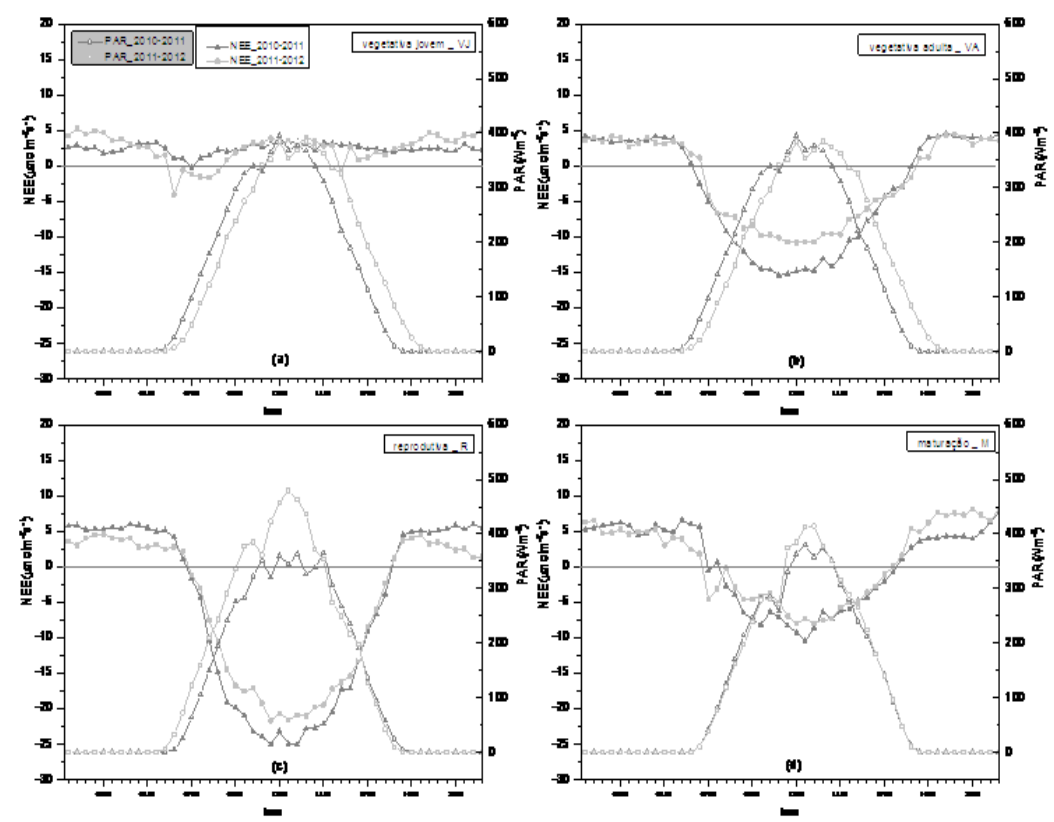

Figura 1 - Variações do ciclo médio diário dos intervalos de 30min de NEE e PAR para cada fase de desenvolvimento do arroz. Os triângulos representam o NEE e PAR para o sítio experimental no cultivo de 2010_2011. Os quadrados representam o NEE e PAR para o cultivo de 2011-2012. (a) fase vegetativa jovem (VJ), (b) fase vegetativa adulta (VA), (c) fase reprodutiva (R), (d) fase de maturação (M). 